\title{
Effects of black carbon morphology on brown carbon absorption estimation: from numerical aspects
}

\author{
Jie Luo, Yongming Zhang, and Qixing Zhang \\ State Key Laboratory of Fire Science, University of Science and Technology of China, Hefei, Anhui 230026, China
}

Correspondence: Qixing Zhang (qixing@ustc.edu.cn)

Received: 15 October 2020 - Discussion started: 5 November 2020

Revised: 30 January 2021 - Accepted: 26 February 2021 - Published: 23 April 2021

\begin{abstract}
In this work, we developed a numerical method to investigate the effects of black carbon (BC) morphology on the estimation of brown carbon $(\mathrm{BrC})$ absorption using the absorption Ångström exponent (AAE) methods. Pseudo measurements of the total absorption were generated based on several morphologically mixed $\mathrm{BC}$ models, then the $\mathrm{BrC}$ absorption was inferred based on different BC AAE methods. By investigating the estimated $\mathrm{BrC}$ absorption at different parameters, we have demonstrated under what conditions the AAE methods can provide good or bad estimations. As recent studies have shown that both externally and internally mixed $\mathrm{BC}$ still exhibits a relatively small fractal dimension value, the $\mathrm{AAE}=1$ method is still a reasonable method to estimate the $\mathrm{BrC}$ absorption as the AAE of fluffy $\mathrm{BC}$ does not deviate significantly from 1 . However, the deviation between the "true" and the estimated $\mathrm{BrC}$ mass absorption cross section (MAC) should also be carefully considered as sometimes the MAC deviation estimated using the $\mathrm{AAE}=1$ method can reach a value that is comparable to the true BrC MAC for internally mixed particles. The Mie AAE method can just provide relatively reasonable estimations for small particles, and the $\mathrm{BrC}$ absorption deviations estimated using the Mie AAE methods are rather substantial for large particles. If the $\mathrm{BC}$ core still exhibits a fluffy structure, the deviation between the true and the estimated $\mathrm{BrC}$ MAC can reach 4.8 and $5.8 \mathrm{~m}^{2} / \mathrm{g}$ for large externally and internally mixed particles, respectively. Even for a compact $\mathrm{BC}$ core, the BrC MAC deviation estimated using the Mie AAE method can reach approximately $2.8 \mathrm{~m}^{2} / \mathrm{g}$ when the $\mathrm{BC}$ size is large. By comparing the $\mathrm{AAE}$ of spherical $\mathrm{BC}$ and detailed $\mathrm{BC}$ models, we found that the AAE does not deviate significantly from 1 if $\mathrm{BC}$ presents a fluffy fractal structure, while it varies considerably with particle size if $\mathrm{BC}$ exhibits a spher-
\end{abstract}

ical structure, and the AAE value of spherical BC can vary from a negative value to approximately 1.4. The precalculated wavelength dependence of AAE (WDA) method does not necessarily improve the estimations. In many cases, the WDA method even provides a worse estimation than the BC $\mathrm{AAE}=1$ and Mie AAE methods. Our results showed that the WDA does not deviate significantly from 0 if the $\mathrm{BC}$ core presents a fluffy structure, while the WDA of spherical BC can vary significantly as the particle size changes. The deviation between the true and the estimated $\mathrm{BrC}$ MAC using the WDA method can reach approximately $9 \mathrm{~m}^{2} / \mathrm{g}$ for externally mixed particles, which is far more than $\mathrm{BrC}$ MAC itself. As recent studies have shown that $\mathrm{BC}$ commonly exhibits a fluffy structure but not a spherical structure, the estimation of $\mathrm{BrC}$ absorption based on the AAE method should carefully consider the effects of $\mathrm{BC}$ morphologies.

\section{Introduction}

Carbonaceous aerosols, a main source of the light-absorbing aerosols, have great effects on the climate. Carbonaceous aerosols mainly include black carbon (BC) and organic carbon (OC). BC was considered the dominant absorbing aerosol in the atmosphere, which greatly absorbs light from ultraviolet (UV) wavelengths to near-infrared wavelengths, and it contributes to large warming effects on the climate (IPCC, 2013). OC was often regarded as a scattering aerosol, while many studies have shown that parts of OC can also strongly absorb light at UV wavelengths (Kirchstetter et al., 2004; Chakrabarty et al., 2010; Chen and Bond, 2010), and the absorbing $\mathrm{OC}$ is called brown carbon $(\mathrm{BrC})$. To figure out the climate effects of $\mathrm{BrC}$, many modeling studies have been 
examined. $\mathrm{BrC}$ was estimated to contribute to approximately $20 \%-40 \%$ of the total aerosol absorption, and its direct radiative effect has been estimated to be comparable to that of BC (Feng et al., 2013; Saleh et al., 2015). However, substantial uncertainties exist in the climate modeling of $\mathrm{BrC}$ (Wang et al., 2016). The accurate estimation of $\mathrm{BrC}$ demands the constraints from the observation.

Laboratory measurements based on the extraction of filter samples were widely used to measure $\mathrm{BrC}$ absorption, while it is difficult to provide global, continuous measurements. Thus, an increasing number of studies used measurements based on remote sensing and in situ techniques. However, the observed absorptions commonly come from the mixing of different aerosols. To separate the contributions of different aerosols, some attempts were made to derive the $\mathrm{BrC}$ contribution from the total absorption (Wang et al., 2016, 2018; Russell et al., 2010; Massabò et al., 2015; Bahadur et al., 2012; Chung et al., 2012). Dust, BC, and BrC are widely accepted to be the main absorbing aerosols in the atmosphere. Dust is recognized to be in the coarse mode, while $\mathrm{BrC}$ and $\mathrm{BC}$ are commonly in fine size mode. Therefore, based on the size information inferred from remote sensing using different techniques (e.g., the extinction Ångström exponent, EAE), the dust and other absorbing aerosols can be separated. However, it is difficult to separate $\mathrm{BC}$ and $\mathrm{BrC}$ based on the size information. To quantify the absorption contribution of $\mathrm{BrC}$ in the fine mode, a typical method was commonly used based on the strong spectral dependence of $\mathrm{BrC}$ from UV to near-infrared wavelengths. $\mathrm{BrC}$ is commonly seen to be non-absorbing at the near-infrared wavelengths, so the total fine aerosol absorption in near-infrared wavelengths comes completely from $\mathrm{BC}$ absorption (excluding dust). In UV wavelengths, the total absorption should be the sum of $\mathrm{BrC}$ and $\mathrm{BC}$ absorption, and the $\mathrm{BrC}$ absorption is the difference between the total absorption and $\mathrm{BC}$ absorption. Therefore, the derivation of the $\mathrm{BrC}$ absorption suffers large uncertainties from $\mathrm{BC}$ properties. The most widely used method to estimate the $\mathrm{BrC}$ absorption is based on the $\mathrm{BC}$ absorption Ångström exponent (AAE), which represents the spectral dependence of the absorption. Given two wavelengths ( $\lambda_{1}$ and $\lambda_{2}$ ), the BC AAE at the corresponding wavelength pair can be calculated using the following:

$$
\mathrm{AAE}=-\frac{\ln \left(\frac{\operatorname{abs}\left(\lambda_{1}\right)}{\operatorname{abs}\left(\lambda_{2}\right)}\right)}{\ln \left(\frac{\lambda_{1}}{\lambda_{2}}\right)},
$$

where $\operatorname{abs}\left(\lambda_{1}\right)$ and $\operatorname{abs}\left(\lambda_{2}\right)$ represent the absorptions at $\lambda_{1}$ and $\lambda_{2}$, respectively. Given the AAE value of $\mathrm{BC}$, the $\mathrm{BC}$ absorption at UV wavelengths can be obtained based on the absorption at near-infrared wavelengths. However, there are large uncertainties in the estimation of $\mathrm{BC}$ AAE. BC $\mathrm{AAE}=1$ is widely assumed, while the particle size, morphology, and mixing states have significant impacts on BC AAE values (Kirchstetter et al., 2004; Schnaiter et al., 2003;
Li et al., 2016; Liu et al., 2018; Zhang et al., 2020; Liu and Mishchenko, 2018). For example, for bare BC, Schnaiter et al. (2003) reported an average AAE value of approximately 1.1 for diesel BC aerosols; Kirchstetter et al. (2004) have shown BC AAE was approximately $0.6-1.3$ for BC near the roadway or in the tunnel. Recent studies have realized that $\mathrm{BC}$ morphology, particle size, and mixing states can lead to sizable uncertainties in BC AAE (Li et al., 2016; Lack and Cappa, 2010; Liu et al., 2018; Luo et al., 2020). A recent study conducted by Wang et al. (2016) used the Mie calculation to constrain the effects of particle size on the AAE, while a spherical BC morphology was assumed. In their study, a precalculated wavelength dependence of AAE (WDA) based on Mie calculations was used, while the effects of $\mathrm{BC}$ morphology were not considered. In the atmosphere, $\mathrm{BC}$ presents rather complex morphologies based on the observation of electron microscopy images (China et al., 2013; Wang et al., 2017). To estimate $\mathrm{BrC}$ absorption based on measurements from satellite or ground-based measurements, previous studies have developed some techniques to constrain the aerosol refractive index and aerosol type (Tesche et al., 2011; Arola et al., 2011). However, most studies have neglected the effects of BC morphologies. Even though recent studies have also shown that $\mathrm{BC}$ morphologies can affect BC AAE, few studies have provided direct evidence on how large the deviations caused by $\mathrm{BC}$ morphologies will be for the estimation of $\mathrm{BrC}$ absorption.

As measurements in the atmosphere are caused by many factors including particle size, refractive index, mixing states, morphologies, etc., it is difficult to figure out how $\mathrm{BC}$ morphologies affect $\mathrm{BrC}$ absorption derivation. Moreover, it is hard to quantify the deviations due to the effects of aerosol composition and size distributions (Li et al., 2009). As many studies have shown that $\mathrm{BC}$ complex morphologies can have an important impact on the BC optical properties, some studies guessed that the AAE methods may not provide inaccurate estimations. However, few studies have provided direct evidence to prove their assumptions, and the simplified methods were still widely used. In many cases, we can expect that the simplified models may lead to deviations, but we cannot expect how large the deviations caused by the simplified models will be. By using the real measurements, we cannot also expect under what circumstances the simplified models will lead to large deviations, and it is difficult to analyze how the deviations are caused.

Numerical tools have an edge on revealing the complex factors that affect the measurements and can be the supplements for the measurements. In this work, we replaced the complex measurements in the atmosphere with the wellconstrained pseudo absorption "measurements" computed using morphologically realistic mixed models, and the inferred $\mathrm{BrC}$ absorptions based on the $\mathrm{BC} \mathrm{AAE}=1$, Mie $\mathrm{AAE}$, and Mie wavelength-dependent AAE methods were compared with the "true" BrC absorption. Also, the causes of the deviations were analyzed, and the method used in this work 


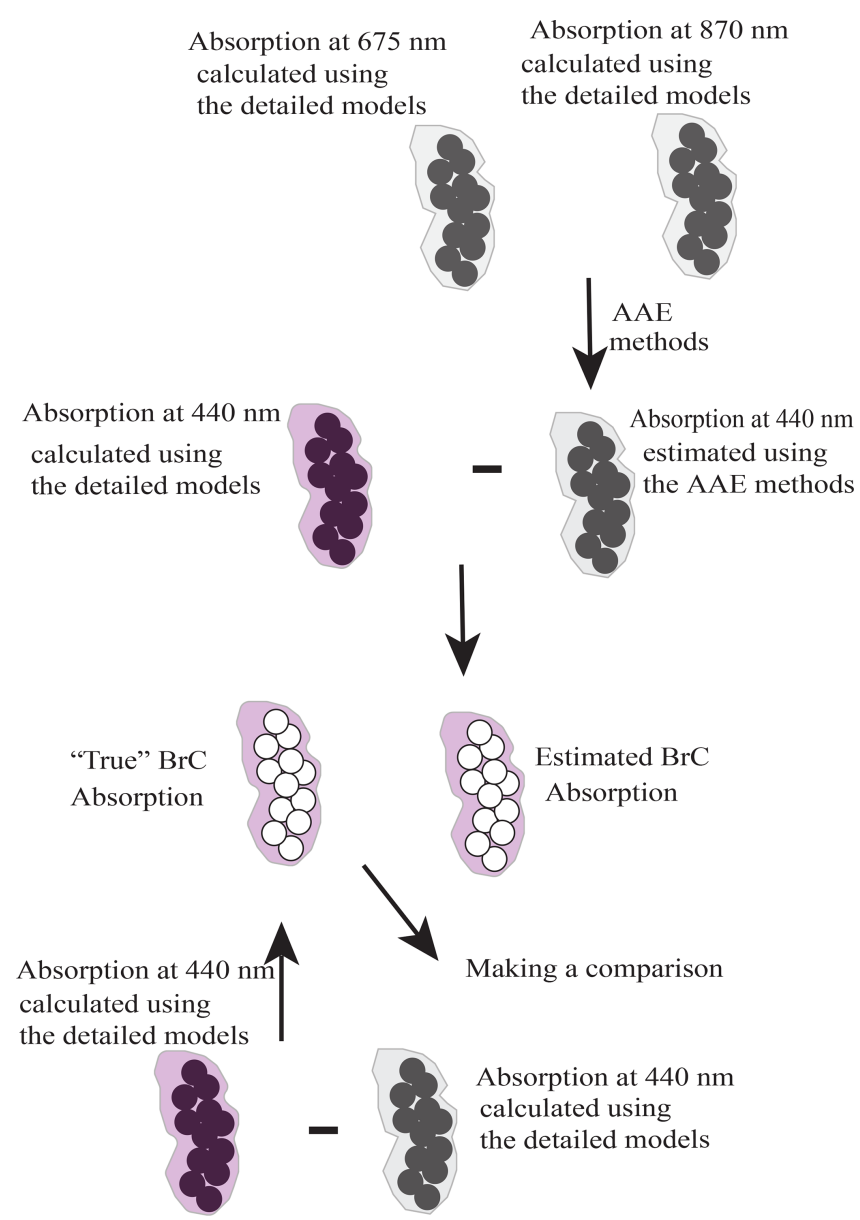

Figure 1. The estimation of $\mathrm{BrC}$ absorption.

is shown in Fig. 1. By using this inverse framework, we intend to answer the following questions.

1. If $\mathrm{BC}$ presents a complex morphology, how large will deviations in the estimation of $\mathrm{BrC}$ absorption caused by the commonly used AAE methods be?

2. Under what conditions can the simplified methods provide bad or good estimations?

3. How are the deviations between the true and the estimated $\mathrm{BrC}$ absorption using simplified models caused?

\section{Pseudo measurements}

\subsection{Morphologies}

Non-spherical aerosol models show more excellent performance on reproducing the measurements even though the Mie theory was commonly used in remote sensing and climate modeling (Bi et al., 2018; He et al., 2016, 2015; Chakrabarty et al., 2007; Luo et al., 2019). In the atmosphere,
$\mathrm{BC}$ can be mixed with $\mathrm{BrC}$, and the mixing states are commonly divided into externally mixed and internally mixed. For the externally mixed particles, each chemical component is separated, and the $\mathrm{BrC}$ and $\mathrm{BC}$ absorption can be treated individually. However, in many cases, $\mathrm{BC}$ and $\mathrm{BrC}$ can be internally mixed. As $\mathrm{BC}$ is internally mixed with $\mathrm{BrC}$, the total absorption can be enhanced by the "lensing effect" (Bond and Bergstrom, 2006; Lack et al., 2009) or weakened by the "sunglass effect" (Luo et al., 2018b).

The pseudo measured absorptions were calculated based on the morphologically realistic BC models. For the externally mixed particles, a fractal morphology was assumed for $\mathrm{BC}$, and the structures satisfy the fractal law (Sorensen, 2001; Mishchenko et al., 2002):

$N_{s}=k_{0}\left(\frac{R_{g}}{R}\right)^{D_{\mathrm{f}}}$,

where $N_{S}$ and $R$ represent the monomer number and mean monomer radius, respectively, $D_{\mathrm{f}}$ denotes the fractal dimension, and larger $D_{\mathrm{f}}$ generally represents more compact aggregates, and $k_{0}$ represents the fractal prefactor, and it mainly affects the shape anisotropy. $R_{\mathrm{g}}$ represents the gyration radius. To generate $\mathrm{BC}$ aggregates, a tunable algorithm was applied (Woźniak, 2012). In the tunable code, $k_{0}$ and $D_{\mathrm{f}}$ are fully adjustable, and the fractal law is strictly satisfied in each growth step.

Bond and Bergstrom (2006) have demonstrated that the observed monomer radius was commonly in the range of $10-25 \mathrm{~nm}$. However, previous studies have shown that the mass absorption cross sections (MACs) of $\mathrm{BC}$ are insensitive to the $\mathrm{BC}$ monomer radius as $\mathrm{BC}$ monomer radius is in the range of 10-25 nm (Kahnert, 2010; Liu and Mishchenko, 2005). Therefore, similar to Luo et al. (2018b, c), a constant monomer radius of $20 \mathrm{~nm}$ was assumed. As both fluffy and compact BC exist in the atmosphere, we used $D_{\mathrm{f}}=1.8$ and $D_{\mathrm{f}}=2.6$ to represent the fluffy and compact BC, respectively. Even though the $k_{0}$ was also observed in a relatively wide range, when $D_{\mathrm{f}}=1.82$, Liu and Mishchenko (2005) indicated that with $k_{0}$ increasing from approximately 0.9 to approximately 2.1 , the BC MAC did not vary substantially. In this work, we fixed $k_{0}$ to be 1.2. According to Zhang et al. (2008), we used mobility diameters of $155 \mathrm{~nm}$ and $320 \mathrm{~nm}$ to represent small and large BC, respectively. As BC shape is irregular, we substituted the volume mean $\mathrm{BC}$ diameter $\left(D_{\mathrm{V}}=2 R\left(N_{s}\right)^{1 / 3}\right)$ for the mobility diameter. The corresponding $N_{s}$ values are 58 and 512, respectively. The morphology of externally mixed $\mathrm{BrC}$ was assumed to be spherical as externally mixed $\mathrm{BrC}$ commonly exists as the spherical tar balls (Chakrabarty et al., 2010). BC refractive index can vary with wavelengths, while Bond and Bergstrom (2006) have shown that the $\mathrm{BC}$ refractive index does not vary greatly from the wavelengths from the ultraviolet to near-infrared regions. In addition, this study mainly focuses on the effects of $\mathrm{BC}$ morphology, and the variation in $\mathrm{BC}$ refractive index is 
not considered, so we assumed a constant value for the $\mathrm{BC}$ refractive index. Bond and Bergstrom (2006) have suggested five values for the $\mathrm{BC}$ refractive indices, and we used the median value of $1.85+0.71 i$ in this work. The real part of the $\mathrm{BrC}$ refractive index was assumed to be 1.55 (Chakrabarty et al., 2010).

For the internally mixing particles, the BC-containing morphologies were generated based on the models proposed by Luo et al. (2019). Here we simply describe the algorithm to generate the internally mixing particles. Firstly, we have generated the bare $\mathrm{BC}$ aggregates using the tunable code, and the bare $\mathrm{BC}$ aggregates were discretized into numerous dipoles. Then the coating materials were added based on two coating methods. The first coating method identifies the edge dipoles (BC surface) first, and then adds the coating materials based on a parameter $q$ (Luo et al., 2019):

$q=\sum_{i=1}^{N_{\mathrm{d}}} \frac{1}{L_{i}^{k}}$

where $N_{\mathrm{d}}$ is the number of edge dipoles, and $L_{i}$ represents the distance between an exterior dipole and the center of the $i$ th edge dipole. The exterior dipole with a larger $q$ value is more easily filled with coating materials; $k$ is a tunable parameter, and with larger $k$, the coating materials more easily fill the dipoles surrounding the edge dipoles. In this study, $k=8$ was assumed, and the generated $\mathrm{BC}$ model was referred to as Model A.

The second coating method adds the coating materials based on another parameter (Luo et al., 2019):

$p=\sum_{i=1}^{N_{\mathrm{c}}} \frac{1}{l_{i}^{2}}$,

where $N_{\mathrm{c}}$ represents the BC monomer number within a defined sphere with a radius of $R_{\mathrm{c}}$. The defined sphere can represent the uneven distribution of coating materials, and $l_{i}$ represents the distance between an exterior dipole and the center of the $i$ th monomer sphere. The exterior dipole with a larger $q$ value is assumed to be more easily filled with coating materials. In the second coating method, $R_{\mathrm{c}}$ is assumed to be adjustable, and smaller $R_{\mathrm{c}}$ can reflect more spherical coating materials. In this work, $R_{\mathrm{c}}=50 R_{\mathrm{g}}$ and $R_{\mathrm{c}}=R_{g}$ were assumed to represent the film and spherical coatings and are named Model B and Model C, respectively. In our previous study (Luo et al., 2019), we have demonstrated that our proposed models can greatly simulate the internally mixed $\mathrm{BC}$ morphologies and reproduce the measured absorption as well. For more details about the algorithm to generate the coated BC, please refer to Luo et al. (2019), and the typically generated morphologies are shown in Fig. 3 and figs. S1-S2 in Luo et al. (2019).
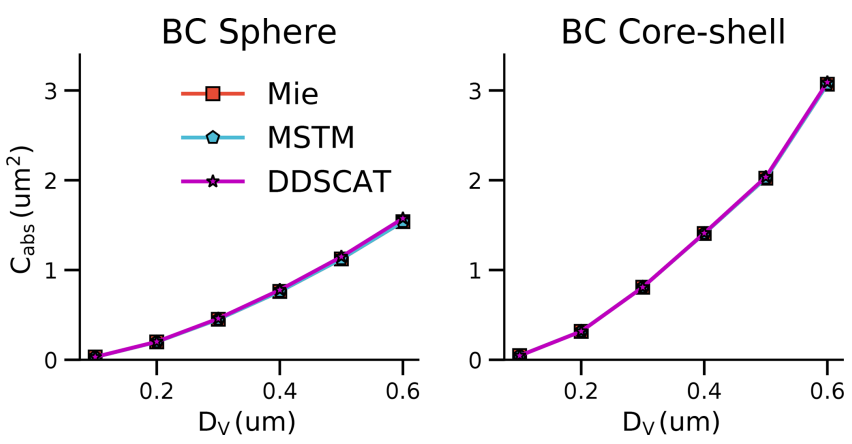

Figure 2. The absorption cross sections of spherical BC calculated using the Mie theory, MSTM, and DDA. For the BC core sphere, the ratio of the shell radius to the core radius was assumed to be 1.5 .

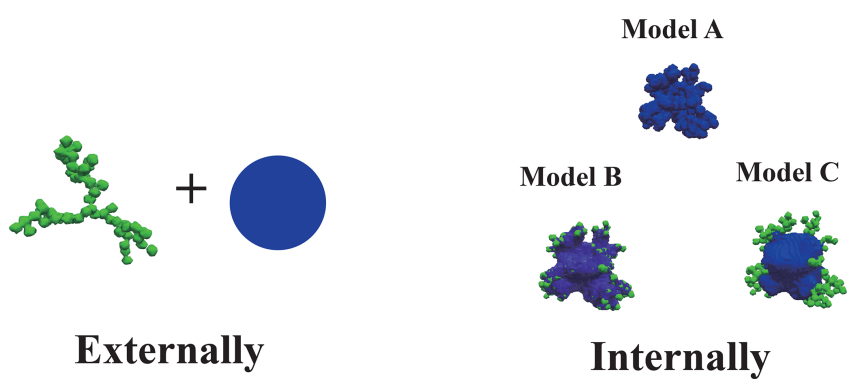

Figure 3. BC morphologies considered in this work. The internally mixed particles were generated using the models developed by Luo et al. (2019).

\subsection{Generation of pseudo measurements}

The Mie theory (Mie, 1908), the multiple-sphere T-matrix (MSTM) method (Mackowski and Mishchenko, 2011, 1996), and the discrete dipole approximation (DDA) method (Draine and Flatau, 2008, 1994) are widely used to calculate the optical properties of black carbon. The Mie theory is the most efficient method, but it is just applicable to spherical particles. MSTM was developed to calculate the optical properties of multiple spheres. Compared to DDA, it calculates analytically the optical properties of randomly oriented particles without numerically averaging over particle orientations. So MSTM is more efficient and accurate than DDA. Bare BC is widely assumed to be composed of numerous spherical monomers which can be calculated using the MSTM. Therefore, we used the MSTM to calculate the optical properties of bare BC, and MSTM version 3 was used in this work. However, as $\mathrm{BC}$ is coated with $\mathrm{BrC}$, the mixed-particle morphology becomes extremely complex, and it is difficult to fit the particle morphology using a group of spheres. DDA has an edge on calculating the optical properties of particles with arbitrary shapes. Therefore, we used the DDA to calculate the optical properties of internally mixed particles. In this work, we used DDSCAT version 7.3 (Draine and Flatau, $2008,1994)$. We assumed that BC is randomly oriented in 
the atmosphere (Mishchenko and Yurkin, 2017), and the results were averaged over $12 \times 7 \times 12=1080$ directions. In DDSCAT, the accuracy of the calculation depends significantly on the dipole spacing $(d)$. In this work, all the calculations satisfy $|m| k_{\mathrm{W}} d<0.23$, where $m$ and $k_{\mathrm{W}}$ are the refractive index of BC and wavenumber, respectively.

In MSTM and DDSCAT, the total absorption efficiency ( $\left.Q_{\text {abs }}\right)$ of particles was directly outputted. In MSTM and DDSCAT, $Q_{\text {abs }}$ was defined with respect to the volume mean radius, so the absorption cross section $\left(C_{\text {abs }}\right)$ can be obtained using the following:

$C_{\mathrm{abs}}=\frac{1}{4} Q_{\mathrm{abs}} \pi D_{\mathrm{V}}^{2}$

To verify the accuracy of MSTM and DDSCAT, we have compared the $C_{\text {abs }}$ of spherical BC calculated using the Mie theory, MSTM, and DDSCAT. The Mie calculations were performed using the PyMieScatt package (Sumlin et al., 2018). As shown in Fig. 2, the $C_{\text {abs }}$ of spherical BC calculated using different numerical methods are in great agreement. The deviations between MSTM and Mie calculations are less than $0.1 \%$. For bare BC, the deviations between DDSCAT and Mie calculations are less than $2 \%$, and for core-shell BC, the deviations between DDSCAT and Mie calculations are less than $1 \%$. The deviations are acceptable compared to the deviations between the true and inferred $\mathrm{BrC}$ absorption.

In real circumstances, the total absorptions can be inferred from the observations or measurements. Thus, the total absorption cross section was used to provide pseudo measurements. For the internally mixed particles, the total absorption cross section can be directly obtained from the calculations based on the morphologically realistic models. For the externally mixed particles, the total absorption cross section is the sum of the absorption cross section of $\mathrm{BC}$ and $\mathrm{BrC}$.

\section{Inferring the $\mathrm{BrC}$ absorption}

\subsection{True BrC absorption}

In the study of Luo et al. (2018b), by separating the absorption of $\mathrm{BC}$ and $\mathrm{BrC}$, they found the total absorption of the internally mixed particles can be less than the sum of $\mathrm{BrC}$ and $\mathrm{BC}$ absorption calculated individually. So there must be a negative effect to weaken the total absorption. From physical points, Luo et al. (2018b) found that the $\mathrm{BrC}$ absorption can block the solar radiation deeply into BC and so weaken the total absorption, and the effect was named the sunglass effect. In addition, the lensing effect was redefined as the absorption enhancements of $\mathrm{BC}$ by the addition of non-absorbing coating materials. Therefore, the total absorptions of mixed particles consist of $\mathrm{BC}$ absorption, $\mathrm{BrC}$ absorption, the lensing effect, and the sunglass effect. However, both the sunglass effect and $\mathrm{BrC}$ shell absorption are caused by absorbing BrC. For convenient application, the true $\mathrm{BrC}$ absorption was assumed as the difference between the absorption of $\mathrm{BC}$ mixed with $\mathrm{BrC}$ and $\mathrm{BC}$ mixed with non-absorbing materials. Here we must clarify that the true $\mathrm{BrC}$ absorption in this work is the co-effect of the absorption $\mathrm{BrC}$ shell and the sunglass effect for internally mixed particles. To eliminate the effect of $\mathrm{BrC}$ mass, the $\mathrm{BrC}$ mass absorption cross section ( $\mathrm{MAC}_{\mathrm{BrC}}$ ) was used, and it can be calculated using the following:

$C_{\text {abs_BrC }}=C_{\text {abs_BC }}$ and $\mathrm{BrC}-C_{\text {abs_BC }}$ and non-absorbing ,

$\mathrm{MAC}_{\mathrm{BrC}}=C_{\text {abs_BrC }} / M_{\mathrm{BrC}}$.

Here $C_{\text {abs_BC }}$ and $\mathrm{BrC}$ and $C_{\mathrm{abs} \_\mathrm{BC}}$ and non-absorbing represent the absorption cross sections of $\mathrm{BC}$ mixed with $\mathrm{BrC}$ and non-absorbing materials, respectively. The morphologies of BC mixed with non-absorbing materials is the same as those mixed with $\mathrm{BrC} ; M_{\mathrm{BrC}}$ represents the mass of $\mathrm{BrC}$, which was calculated using the following:

$M_{\mathrm{BrC}}=V_{\mathrm{BrC}} \rho_{\mathrm{BrC}}$,

$V_{\mathrm{BrC}}=V_{\mathrm{BC}} \cdot\left(1-f_{\mathrm{BC}}\right) / f_{\mathrm{BC}}$,

$V_{\mathrm{BC}}=N_{S} \cdot\left(4 / 3 \pi R^{3}\right)$,

where $V_{\mathrm{BrC}}$ and $V_{\mathrm{BC}}$ represent the volume of $\mathrm{BrC}$ and $\mathrm{BC}$, respectively, $f_{\mathrm{BC}}$ represents the volume fraction of $\mathrm{BC}$, and $\rho_{\mathrm{BrC}}$ represents the mass density of $\mathrm{BrC}$. Even though the estimated $\mathrm{BrC}$ absorption cross section is independent of $\rho_{\mathrm{BrC}}, \mathrm{BrC}$ MAC is significantly affected by $\rho_{\mathrm{BrC}}$. We assumed that the BrC has the same mass density as the typical organic carbon (OC). However, the OC mass density $\left(\rho_{\mathrm{OC}}\right)$ varies in different regions. Even though Turpin and Lim (2001) suggested a typical value of $1.2 \mathrm{~g} / \mathrm{cm}^{3}$ for $\rho_{\mathrm{OC}}$, they also observed a rather low $\rho_{\mathrm{OC}}$ value of $0.87 \mathrm{~g} / \mathrm{cm}^{3}$. In addition, Turpin and Lim (2001) further showed that the reported $\rho_{\mathrm{OC}}$ can vary from approximately 0.77 to approximately $1.9 \mathrm{~g} / \mathrm{cm}^{3}$. In this work, similar to Luo et al. (2018b), we just used the suggested value of $1.2 \mathrm{~g} / \mathrm{cm}^{3}$, and the uncertainties caused by $\rho_{\mathrm{OC}}$ should be further evaluated in the future.

\subsection{Inferring $\mathrm{BrC}$ absorption}

The calculation of inferred $\mathrm{BrC}$ absorption is similar to the true case, while the difference in the $C_{\text {abs_BC }}$ and non-absorbing is inferred from an assumed AAE.

$$
\begin{aligned}
& C_{\text {abs_BC_non-absorbing } 2}=C_{\text {abs_BC_non-absorbing1 } 1} \\
& \cdot\left(\frac{\lambda_{2}}{\lambda_{1}}\right)^{-\mathrm{AAE}}
\end{aligned}
$$

Here $C_{\text {abs_BC_non-absorbing1 }}$ and $C_{\text {abs_BC_non-absorbing2 }}$ are the corresponding absorption cross section of $\mathrm{BC}$ with nonabsorbing materials at $\lambda_{1}$ and $\lambda_{2}$, respectively.

The total absorption observations at 440,675 , and $870 \mathrm{~nm}$ wavelengths can be commonly obtained in AERONET and 
other ground measurements. Based on the strong spectral dependence of $\mathrm{BrC}, \mathrm{BrC}$ absorption at 675 and $870 \mathrm{~nm}$ wavelengths are commonly neglected, and the absorptions at 675 and $870 \mathrm{~nm}$ wavelengths come fully from the $\mathrm{BC}$ absorption. As BC absorption at $440 \mathrm{~nm}$ wavelength can be obtained based on the BC AAE, we can estimate the BrC absorption at $440 \mathrm{~nm}$ based on Eq. (6). In this work, we inferred the mass absorption cross section (MAC) of $\mathrm{BrC}$ at $440 \mathrm{~nm}$ wavelength based on the pseudo measurements at 675 and $870 \mathrm{~nm}$ wavelengths using $\mathrm{BC} \mathrm{AAE}=1$ and $\mathrm{AAE}$ of Mie calculations. For the Mie AAE methods, we have precalculated the AAE of $\mathrm{BC}$ with a spherical structure (BC sphere or $\mathrm{BC}$ core shell) by assuming an identical volume mean diameter for the non-spherical BC using MSTM.

In addition, Wang et al. (2016) proposed a method to derive $\mathrm{BrC}$ absorption based on the AAE spectral dependence (WDA) using Mie calculations. The WDA was calculated using the following:

$\mathrm{WDA}=\mathrm{AAE}_{\lambda 1 \_\lambda 2}-\mathrm{AAE}_{\lambda 2 \_\lambda 3}$,

where $\mathrm{AAE}_{\lambda 1_{-} \lambda 2}$ and $\mathrm{AAE}_{\lambda 2 \_\lambda 3}$ are the $\mathrm{AAE}$ values calculated based on different wavelength pairs. Based on the particle sizes and refractive index, the WDA was precalculated by assuming a spherical particle morphology, and then the $\mathrm{AAE}$ at a wavelength pair is inferred from AAE at another wavelength pair and precalculated WDA. As for the spherical $\mathrm{BC}$, the optical properties are also calculated using MSTM but not the Mie method for convenience. However, the deviations between MSTM and the Mie method for spherical $\mathrm{BC}$ are rather small, as shown in Fig. 2. In this work, the WDA is calculated using MSTM by assuming a spherical morphology, and then the AAE values between UV and nearinfrared wavelengths are inferred from WDA and AAE at near-infrared wavelengths. Take the wavelengths of 440, 675, and $870 \mathrm{~nm}$, for example. AAE between 440 and $675 \mathrm{~nm}$ can be calculated.

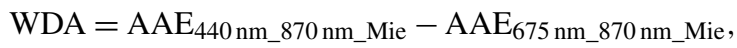

$$
\begin{aligned}
& \mathrm{AAE}_{440} \mathrm{~nm} \_870 \mathrm{~nm} \_ \text {inferred }=\mathrm{AAE}_{675 \mathrm{~nm} \_870 \mathrm{~nm} \_ \text {True }} \\
& + \text { WDA, }
\end{aligned}
$$

where $\mathrm{AAE}_{\mathrm{Mie}}$ is the $\mathrm{AAE}$ of spherical $\mathrm{BC}$ with the same volume mean diameter as the true case, and $\mathrm{AAE}_{\text {inferred }}$ and $\mathrm{AAE}_{\text {True }}$ are the inferred $\mathrm{BC} \mathrm{AAE}$ and the $\mathrm{AAE}$ calculated using the detailed $\mathrm{BC}$ models, respectively. For the inverse of $\mathrm{BrC}$ absorption, all of the WDA was calculated based on the spherical $\mathrm{BC}$ by assuming an identical volume mean diameter for the non-spherical BC, and we call it the WDA method. We have also demonstrated the effects of morphologies on the applicability of the WDA method. The true BrC absorption cross section $\left(C_{\text {abs_BrC_True }}\right)$ and the estimated $\mathrm{BrC}$ absorption cross section $\left(C_{\text {abs_BrC_Estimated }}\right)$ can be calculated using the following:

$$
\begin{aligned}
& C_{\text {abs_BrC_True }}=C_{\text {abs_BC } \text { and } \mathrm{BrC}} \\
& \quad-C_{\text {abs_BC } \text { and non-absorbing_True }}, \\
& C_{\text {abs_BrC_Estimated }}=C_{\text {abs_BC and }} \mathrm{BrC} \\
& \quad-C_{\text {abs_BC }} \text { and non-absorbing_Estimated }
\end{aligned}
$$

where $\quad C_{\text {abs_BC }}$ and non-absorbing_True and $C_{\text {abs_BC and non-absorbing_Estimated }}$ represent the true and estimated absorption cross sections of $\mathrm{BC}$ mixed with non-absorbing materials, respectively.

As the $\mathrm{BrC}$ absorption estimation is significantly affected by the $\mathrm{BC}$ physical properties, we have also calculated the difference between true and the estimated BrC MAC:

$$
\begin{aligned}
& \delta_{C_{\text {abs }}}=C_{\text {abs_BrC_Estimated }}-C_{\text {abs_BrC_true }} \\
& =C_{\text {abs_BC }} \text { and non-absorbing_True } \\
& -C_{\text {abs_BC } \text { and non-absorbing_Estimated. }} .
\end{aligned}
$$

Here we used a parameter $\delta_{\mathrm{MAC}}$ to represent the difference between true and the estimated $\mathrm{BrC}$ absorption.

$\delta_{\mathrm{MAC}}=\delta_{C_{\mathrm{abs}}} / M_{\mathrm{BrC}}$

As the $\mathrm{BrC}$ MAC deviation between true and inferred $\mathrm{BrC}$ absorption is mainly caused by the inaccurate estimation of $\mathrm{BC}$ absorption, $\delta_{\mathrm{MAC}}$ can represent the deviation between the true and inferred $\mathrm{BrC} \mathrm{MAC}$.

\section{Results}

\subsection{Externally mixed particles}

The BrC MAC significantly depends on the imaginary part of the $\mathrm{BrC}$ refractive index. The measured imaginary parts of $\mathrm{BrC}$ refractive indices varied greatly in different studies in the literature. For example, Nakayama et al. (2013) showed that the secondary $\mathrm{OC}$ generated from the photooxidation of toluene has an imaginary part of refractive index from 0 to 0.0082 and from 0 to 0.0017 at 405 and $532 \mathrm{~nm}$, respectively; Saleh et al. (2013) showed that the imaginary part of primary OC refractive indices was in the range of 0.0055 0.06 , while the imaginary parts of secondary OC refractive indices varied in the range of $0.01-0.05$. Even though the imaginary part of $\mathrm{BrC}$ refractive index varies in different studies due to different chemical compositions, aging status, and generating process, the reported values were commonly within the range between the values reported by Kirchstetter et al. (2004) and those reported by Chen and Bond (2010). In general, the measured imaginary part of the $\mathrm{BrC}$ refractive index is commonly within the range of approximately $0-0.16$.

The measured $\mathrm{BrC}$ MAC also varied in different studies. The range of from 1.26 to $1.79 \mathrm{~m}^{2} / \mathrm{g}$ at $365 \mathrm{~nm}$ wavelength was reported by previous studies (Cheng et al., 2011; Du 
et al., 2014; Srinivas et al., 2016), while Cho et al. (2019) reported a mean $\mathrm{BrC}$ MAC of approximately $0.7 \mathrm{~m}^{2} / \mathrm{g}$ at $565 \mathrm{~nm}$. BrC absorption properties based on laboratory measurements in urban and biomass smoke samples at Lawrence Berkeley National Laboratory showed BrC MAC values of 2.75, 0.95, 0.42, 0.32, and 0.21 at $\lambda=400,500,600,700$, and $900 \mathrm{~nm}$, respectively. In this work, the true BrC MAC is generally within the range of approximately $0-4 \mathrm{~m}^{2} / \mathrm{g}$ as the imaginary part of the $\mathrm{BrC}$ refractive index varies in the range of $0-0.16$. Our calculated $\mathrm{BrC}$ mass absorption cross-section range is a little wider than the measurements as a wide imaginary part range of the $\mathrm{BrC}$ refractive index is assumed.

The comparisons of the true and inferred $\mathrm{BrC}$ absorption for externally mixed particles are shown in Fig. 4. In general, the inferred $\mathrm{BrC}$ MAC agrees relatively well with the true $\mathrm{BrC}$ absorption when the $\mathrm{BC}$ fraction is small. This is easy to be understood. The total effects caused by the $\mathrm{BC}$ morphology are alleviated by the large $\mathrm{BrC}$ fraction, so the effects of $\mathrm{BC}$ morphology on the inferred mass $\mathrm{BrC}$ absorption is small. However, as the ratio of $\mathrm{BC}$ volume to $\mathrm{BrC}$ volume reaches $1: 1$, the inferred $\mathrm{BrC}$ MAC based on the AAE methods may be significantly affected by the $\mathrm{BC}$ morphology. For the large particle, the Mie AAE methods may provide inaccurate estimations for both fluffy and compact particles, and the Mie AAE methods can overestimate the BrC mass absorption by approximately $4.8 \mathrm{~m}^{2} / \mathrm{g}$, which is approximately several times the observed $\mathrm{BrC}$ absorption. For small particles, the $\mathrm{BrC}$ absorption deviations estimated using the Mie AAE methods are relatively small for both fluffy and compact BC. As the morphological effects on the $\mathrm{BrC}$ absorption derivation are significantly dependent on the particle size, we have also investigated $\delta_{\mathrm{MAC}}$ at different particle sizes. As shown in Fig. 5, the accuracy of the Mie AAE method is significantly related to the particle size. Fixing $D_{\mathrm{f}}$ to be 1.8 , while the Mie AAE methods can provide a relatively reasonable estimation for small particles, the $\delta_{\mathrm{MAC}}$ can increase with $D_{\mathrm{V}}$, and it can reach approximately $4.8 \mathrm{~m}^{2} / \mathrm{g}$ when the particle size is large. As shown in Fig. 6, spherical BC AAE depends significantly on the particle size, and the $\mathrm{AAE}$ can reach a negative value for large BC. However, for fractal BC aggregates, the AAE is still around 1 even for large $\mathrm{BC}$, so the Mie AAE methods provide rather inaccurate estimations for large particles.

The applicability of the $\mathrm{BC} \mathrm{AAE}=1$ method should also be carefully considered. As freshly emitted BC commonly exhibits a near fluffy fractal structure (Chakrabarty et al., 2006; Wentzel et al., 2003; China et al., 2015), the AAE $=1$ method can generally provide a reasonable estimation for BrC mixed with freshly emitted BC. As shown in Fig. 4, fixing $D_{\mathrm{f}}$ to be 1.8 , the deviation between the true and the estimated $\mathrm{BrC}$ using the $\mathrm{BC} \mathrm{AAE}=1$ method is not large. The reason is that the AAE of fluffy $\mathrm{BC}$ does not deviate significantly from 1 (see Fig. 6). However, the BC AAE $=1$ method can provide less accurate estimations for $\mathrm{BrC}$ mixed with compact BC. Even though BrC MAC is relatively accurately estimated for small particles, for the large particles, fixing
$f_{\mathrm{BC}}=50 \%$, most of the $\mathrm{BrC}$ mass absorption cross section inferred by assuming $\mathrm{AAE}=1$ is below 0 , and the underestimation of BrC MAC can reach approximately $2.3 \mathrm{~m}^{2} / \mathrm{g}$ as the AAE of large compact BC can be approximately 0.7 (Liu et al., 2018). Therefore, the $\mathrm{BC} \mathrm{AAE}=1$ method is a reasonable method for freshly emitted particles, while it may provide rather inaccurate estimations for $\mathrm{BrC}$ mixed with compact $\mathrm{BC}$ aggregates.

To dispose of the effects of particle size on the AAE method, Wang et al. (2016) proposed a method based on the WDA method to derive $\mathrm{BrC}$ absorption. However, the WDA method does not necessarily provide a better estimation than using the Mie $\mathrm{AAE}$ and $\mathrm{AAE}=1$ methods as the $\mathrm{BC}$ morphology in the atmosphere is rather complex. As shown in Fig. 4, assuming that the BC morphology presents a fractal structure, the WDA method may provide worse estimations than using the $\mathrm{BC} \mathrm{AAE}=1$ method. As shown in Fig. 5, the accuracy of the WDA method is significantly dependent on the particle size. As $D_{\mathrm{V}}$ is approximately $100 \mathrm{~nm}, \mathrm{BrC}$ MAC can be underestimated by approximately $9 \mathrm{~m}^{2} / \mathrm{g}$ using the WDA method. Moreover, the WDA method cannot provide a good estimation even for $\mathrm{BrC}$ mixed with compact $\mathrm{BC}$, and for large particles, the WDA method can provide a worse estimation for $\mathrm{BrC}$ mixed with compact $\mathrm{BC}$ compared to $\mathrm{BrC}$ mixed with fluffy $\mathrm{BC}$. To compare the WDA of spherical $\mathrm{BC}$ and fractal $\mathrm{BC}$, we have calculated the WDA of fractal aggregates with $D_{\mathrm{V}}$ varying from 40 to $400 \mathrm{~nm}$ based on the calculated database from our previous work (Luo et al., 2018a), in which the BC refractive index was assumed to be $m=1.95+0.79 i$. As shown in Fig. 6, the WDA of spherical BC depends largely on the particle size, while the WDA of fractal aggregates does not deviate significantly from zero. Therefore, the effects of $\mathrm{BC}$ morphologies on the applicability of the WDA method should be carefully considered. Moreover, we also notice that even though the true $\mathrm{BrC}$ absorption is larger than 0 , the inferred $\mathrm{BrC}$ absorption can be below 0 as the $\mathrm{BC}$ contents become large. Therefore, we should carefully consider the BC contents when using the AAE method to estimate the $\mathrm{BrC}$ absorption.

\subsection{Internally mixed particles}

As $\mathrm{BC}$ and $\mathrm{BrC}$ are internally mixed, the morphologies become more complex. Not only the fractal parameters (such as $D_{\mathrm{f}}$ ) may change, but also the coating configurations may affect the morphologies. To demonstrate the effect of morphologies, we used three BC models based on different coating configurations to calculate the absorption of the internally mixed particles, as referred to above. As shown in Fig. 7, different $\mathrm{BrC}$ coating shapes may lead to sizable variations in the true $\mathrm{BrC}$ absorption. Fixing the $\mathrm{BrC}$ refractive index to be $1.55+0.08 i$, the variations in the $\mathrm{BrC}$ mass absorption cross section caused by different $\mathrm{BrC}$ coating shapes can vary from 0 to approximately $0.25 \mathrm{~m}^{2} / \mathrm{g}$. Moreover, the particle size and compactness of mixed particles can also have 

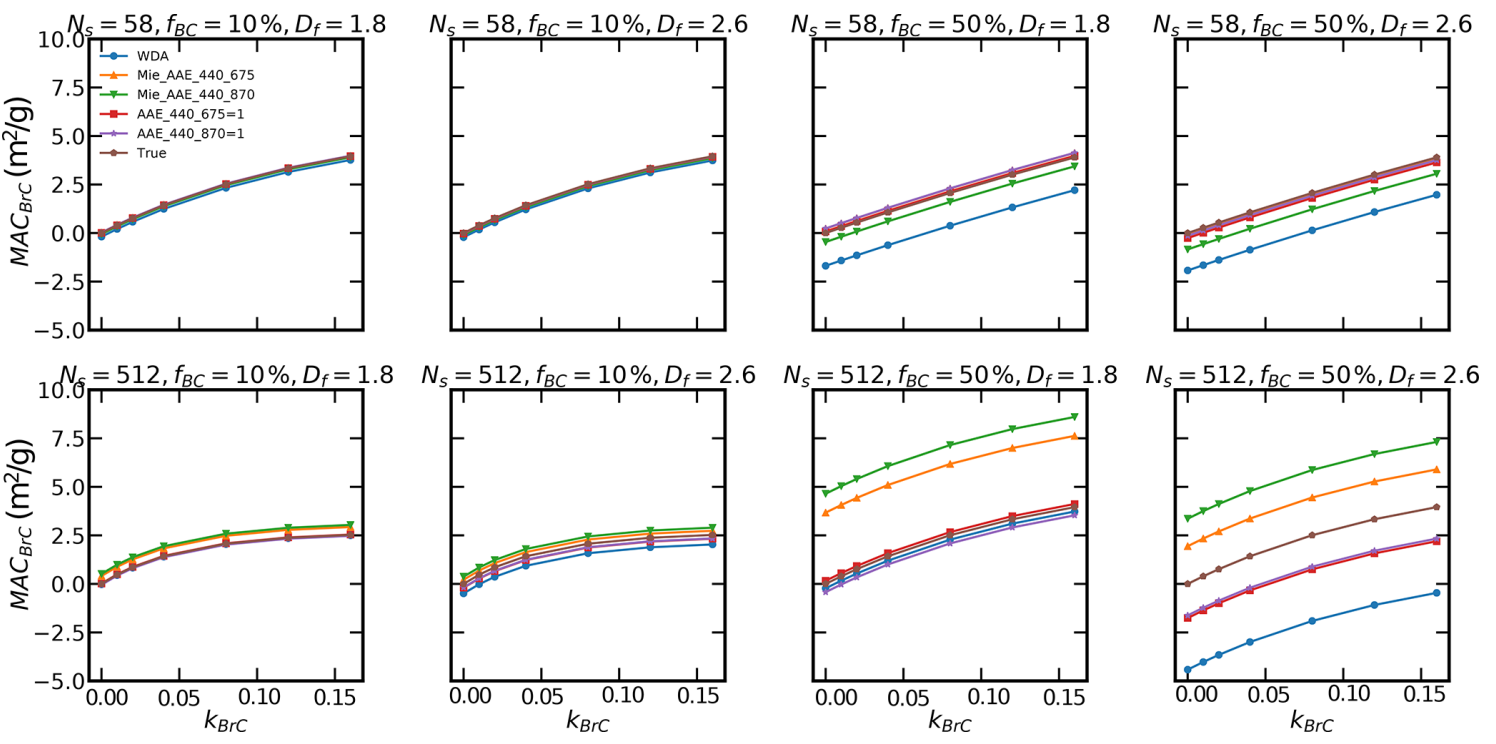

Figure 4. Comparison of the true and inferred $\operatorname{BrC} \operatorname{MAC}(\lambda=440 \mathrm{~nm})$.
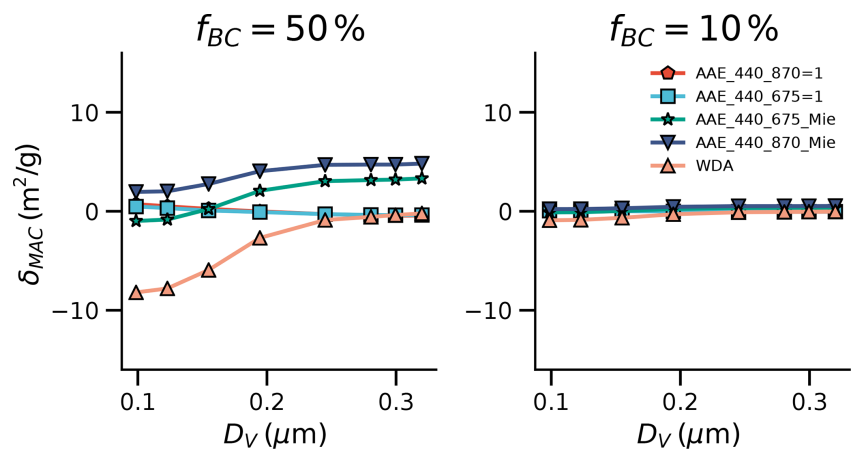

Figure 5. The $\delta_{\mathrm{MAC}}$ values of inferred and true $\mathrm{BrC}$ absorption. Here $D_{\mathrm{V}}$ represents the equivalent volume size of $\mathrm{BC}(\lambda=440 \mathrm{~nm}$, $D_{\mathrm{f}}=1.8$ ).
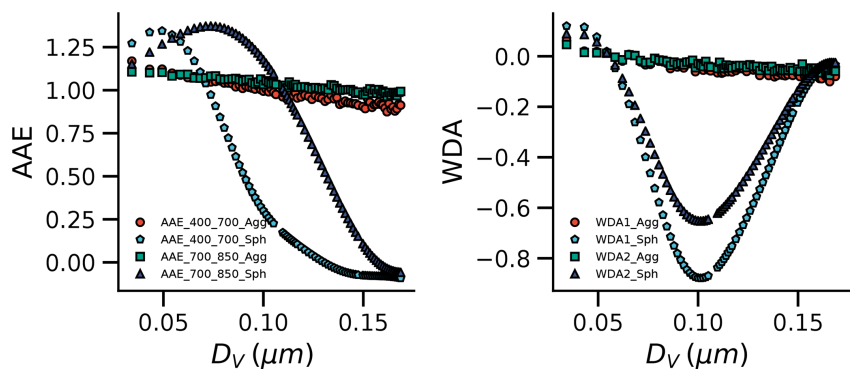

Figure 6. Comparison of AAE and WDA between BC sphere and aggregates $\left(D_{\mathrm{f}}=1.8, m=1.95+0.79 i\right)$. Here WDA1 represents the AAE difference between the 400-700 $\mathrm{nm}$ wavelength pair and the $700-850 \mathrm{~nm}$ wavelength pair; WDA2 represents the difference between the 400-850 nm wavelength pair and the 700-850 nm wavelength pair. "Agg" and "Sph" denote the fractal BC aggregates and spherical BC, respectively.
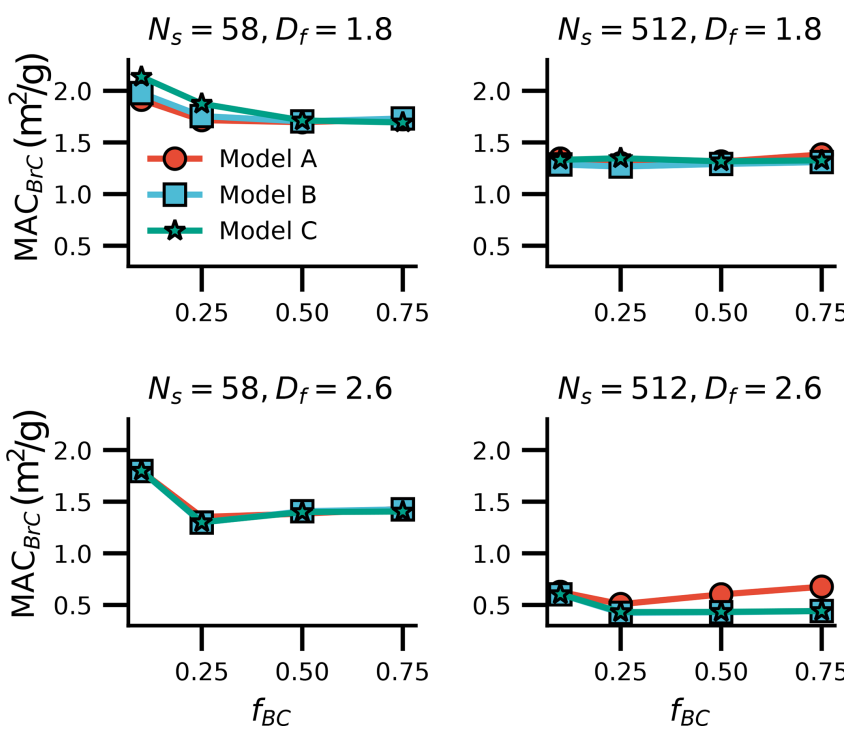

Figure 7. Variation in the true $\mathrm{BrC}$ absorption with different coating models $\left(k_{\mathrm{BrC}}=0.08, \lambda=440 \mathrm{~nm}\right)$.

significant effects on $\mathrm{BrC}$ absorption. Therefore, the determination of $\mathrm{BrC}$ absorption based on the modeling method should consider the variation in $\mathrm{BrC}$ coating shapes for internally mixed $\mathrm{BrC}$ even though most externally mixed $\mathrm{BrC}$ presents a near-spherical shape.

The estimated $\mathrm{BrC}$ MAC also deviates significantly from the true BrC MAC for internally mixed particles. The Mie AAE methods can just provide relatively reasonable estimations for relatively small particles, and for large particles, the inferred $\mathrm{BrC}$ MAC based on the Mie AAE methods even deviates more significantly from true $\mathrm{BrC}$ MAC compared to the externally mixed particles. Fixing $N_{s}$ to be 512 and 
$D_{\mathrm{f}}$ to be 1.8 , the inferred BrC MAC using the Mie AAE at the 440 and $870 \mathrm{~nm}$ wavelength pair can overestimate the true $\mathrm{BrC}$ MAC by approximately $5.8 \mathrm{~m}^{2} / \mathrm{g}$. As also shown in Fig. 9, fixing $D_{\mathrm{f}}$ to be $1.8, \delta_{\mathrm{MAC}}$ estimated based on the Mie AAE methods is relatively small when the particle is small, while it increases to approximately $5.8 \mathrm{~m}^{2} / \mathrm{g}$ when the $\mathrm{D}_{\mathrm{V}}$ of the mixed particles increases to approximately $400 \mathrm{~nm}$. Furthermore, even for heavily coated $\mathrm{BC}\left(f_{\mathrm{BC}}=10 \%\right)$, the Mie AAE method can overestimate the BrC MAC by approximately $1.0 \mathrm{~m}^{2} / \mathrm{g}$ (see both Figs. 8 and 9), which is comparable to the BrC MAC. The Mie AAE method can provide inaccurate estimations even for $\mathrm{BrC}$ mixed with compact BC $\left(D_{\mathrm{f}}=2.6\right)$, and the deviation can reach approximately $2.8 \mathrm{~m}^{2} / \mathrm{g}$ when $f_{\mathrm{BC}}=50 \%$.

The $\mathrm{BC} \mathrm{AAE}=1$ method seems to be still a reasonable method for internally mixed particles with a fluffy BC core. As shown in Fig. 9, fixing $D_{\mathrm{f}}$ to be $1.8, \delta_{\mathrm{MAC}}$ is generally within $-1-1.2 \mathrm{~m}^{2} / \mathrm{g}$, which is much smaller than $\delta_{\text {MAC }}$ estimated using the Mie AAE methods. However, the $\delta_{\text {MAC }}$ estimated using the $\mathrm{AAE}=1$ method can reach a value that is comparable to the $\mathrm{BrC} \mathrm{MAC}$, so it is non-negligible in the estimation of $\mathrm{BrC}$ absorption. Furthermore, as $\mathrm{BC}$ becomes compact, the $\mathrm{AAE}=1$ method may provide more inaccurate estimations, and it can underestimate the BrC MAC by $2-$ $3 \mathrm{~m}^{2} / \mathrm{g}$. The possible reason may be that the AAE of more compact $\mathrm{BC}$ deviates substantially from 1 when $\mathrm{BC}$ size is large, as demonstrated in the study of Liu et al. (2018). Most recent measurements have shown that the average $D_{\mathrm{f}}$ values of both bare and coated BC present a relatively small value. For example, China et al. (2013) found that the $D_{\mathrm{f}}$ of ambient BC emitted from wildfires was generally within the range of 1.75-1.9; China et al. (2014) demonstrated that BC $D_{\mathrm{f}}$ in the freeway was in the range of 1.43-2.1. Yuan et al. (2019) have shown that the BC $D_{\mathrm{f}}$ at a remote site in the southeastern Tibetan Plateau was generally in the range of approximately 1.67-1.93; in the North China Plain, Wang et al. (2017) showed that BC $D_{\mathrm{f}}$ values at background sites, mountaintops, urban sites, and tunnels were generally 1.8 2.16. With a fluffy BC structure, the AAE $=1$ method seems still a reasonable method. However, the $\delta_{\text {MAC }}$ should also be noticed as it can reach a value that is comparable to the $\mathrm{BrC}$ MAC for internally mixed particles. Moreover, some nearspherical BC particles were also observed (e.g., Lewis et al., 2009), which should be carefully considered.

Sometimes the WDA method may even provide worse estimations than the BC AAE $=1$ and Mie AAE methods. Fixing $N_{s}$ to be 58 and $f_{\mathrm{BC}}$ to be $50 \%$, the WDA method can overestimate $\mathrm{BrC}$ MAC by approximately $2 \mathrm{~m}^{2} / \mathrm{g}$, which is comparable to true BrC MAC. As shown in Fig. 9, fixing $D_{\mathrm{f}}$ to be 1.8 , as the particle size of the mixed particles increases, $\delta_{\text {MAC }}$ based on the WDA method increases firstly and then decreases. The WDA method can overestimate the BrC MAC by approximately $2.5 \mathrm{~m}^{2} / \mathrm{g}$ when the $D_{\mathrm{V}}$ of the mixed particles is approximately $200 \mathrm{~nm}$. The reason may be that the WDA calculated using the Mie method overestimates the effect of the BC size. As shown in Fig. 10, even though the WDA of Model A does not deviate significantly from 0, the WDA of the core-shell sphere model depends largely on the particle size. So the Mie WDA can overestimate the effects of the particle size, and the WDA method is obviously limited by the $\mathrm{BC}$ morphologies.

Even though the morphologically realistic models have not been used in the real cases, but based on the BC morphologies collected in the atmosphere, we believe that if we can know the detailed $\mathrm{BC}$ morphologies, we can improve the estimations. Some studies have been conducted to investigate the $\mathrm{BC}$ morphologies in different regions, which can provide information for the estimation of $\mathrm{BrC}$ absorption. For example, by exploring the three-dimensional (3D) electron tomography method, Adachi et al. (2007) have analyzed the morphological characteristics of $\mathrm{BC}$. Based on the two-dimensional (2D) electron tomography image and fractal theory, China et al. (2013) have characterized the BC structures emitted from wildfires. Wang et al. (2017) have investigated the BC morphologies at background sites, mountaintops, urban sites, and tunnels in North China. Moreover, Yuan et al. (2019) have investigated the externally mixed and internally mixed $\mathrm{BC}$ at a remote site in the southeastern Tibetan Plateau. However, we acknowledge that the measurements are still not enough now, and further measurements on the BC morphological information are required to improve the estimation. This study highlights the effects of $\mathrm{BC}$ morphology on the estimation of $\mathrm{BrC}$ absorption, which may further promote the measurements of complex BC morphologies in different regions. By conducting such measurements, we expect to obtain the percentages of different $\mathrm{BC}$ morphologies, and the optical properties will be calculated based on the "average" of different $\mathrm{BC}$ morphologies based on a probability distribution of different $\mathrm{BC}$ morphologies in a real case (Wu et al., 2020). In the future, we expect to use the measured BC morphological information in a real case, while this study focuses on theoretical investigations of the effect of $\mathrm{BC}$ particle morphology on the estimation of $\mathrm{BrC}$ absorption based on commonly used AAE methods.

\section{Conclusions}

Some previous studies have guessed that the AAE methods may not provide inaccurate estimations, but few studies have provided direct evidence to prove their guess. In this work, based on an inverse framework, we provide a relatively new insight to investigate the $\mathrm{BC}$ morphological effect on the estimation of $\mathrm{BrC}$ absorption. To focus on the effects of $\mathrm{BC}$ morphologies, pseudo measurements were generated based on some morphological mixed $\mathrm{BC}$ models, then the $\mathrm{BrC}$ absorption was inferred based on the AAE method. Even though the true $\mathrm{BrC}$ absorption is within the measured range, the inferred $\mathrm{BrC}$ absorption is significantly affected by the $\mathrm{BC}$ morphologies. 

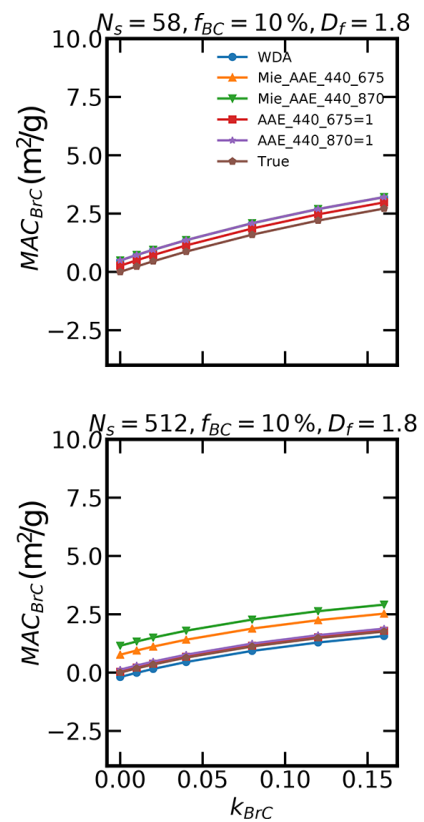
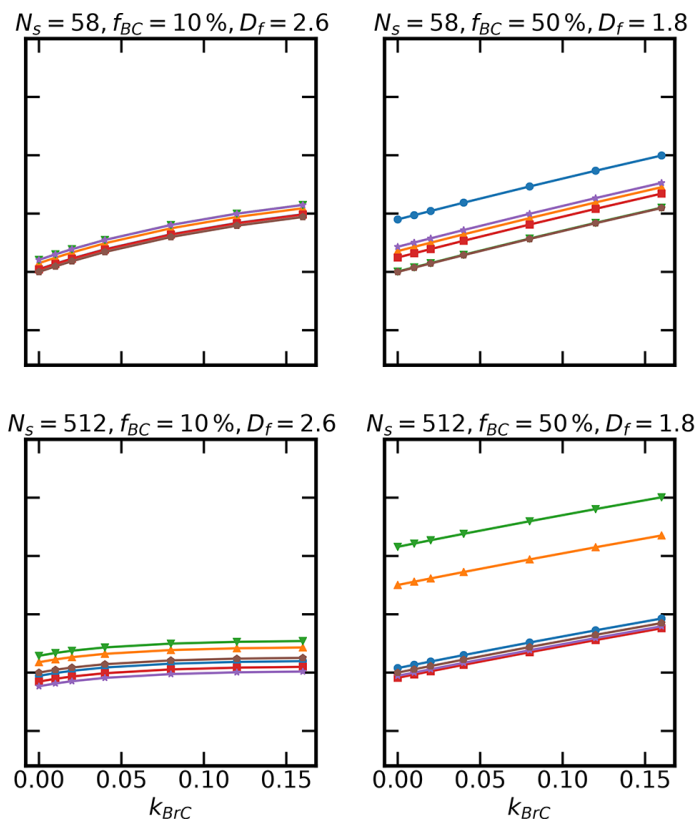
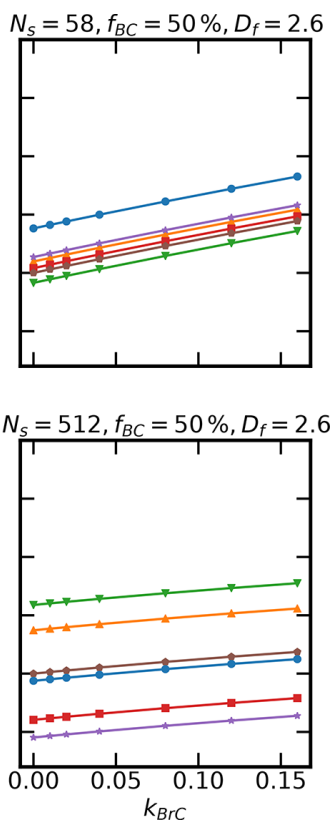

Figure 8. Comparison of the true and inferred $\mathrm{BrC}$ absorption for internally mixed particles (Model A; $\lambda=440 \mathrm{~nm}$ ).
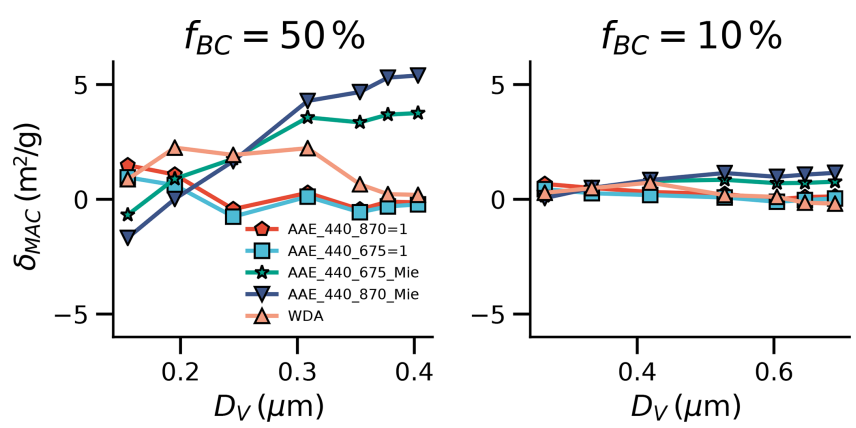

Figure 9. Similar to Fig. 5 but for internally mixed particles $\left(D_{\mathrm{f}}=\right.$ $1.8 ; \lambda=440 \mathrm{~nm})$.

By investigating the estimated $\mathrm{BrC}$ absorption at different parameters, we have demonstrated under what conditions the AAE methods can provide good or bad estimations. Freshly emitted BC commonly presents a fluffy structure, and its $\mathrm{AAE}$ does not deviate significantly from 1 , so the $\mathrm{BC} \mathrm{AAE}=1$ method can provide reasonable estimations. For the internally mixed particles, as most recent studies have demonstrated that the $D_{\mathrm{f}}$ of coated $\mathrm{BC}$ also exhibits a relatively small value, the $\mathrm{BC} \mathrm{AAE}=1$ method is still a reasonable selection. However, the deviation between the true and the estimated $\mathrm{BrC}$ MAC should also be carefully considered if $\mathrm{BC}$ exhibits a complex morphology as sometimes the $\delta_{\mathrm{MAC}}$ estimated using the $\mathrm{BC} \mathrm{AAE}=1$ method can reach a value that is comparable to the true $\mathrm{BrC} \mathrm{MAC}$. The Mie AAE methods can just provide relatively reasonable estimations for small particles, and the $\mathrm{BrC}$ absorption deviations estimated using the Mie AAE methods are rather substantial for large particles. If the $\mathrm{BC}$ core still exhibits a fluffy structure, the deviation between the true and the estimated $\mathrm{BrC}$ MAC using the Mie AAE methods can reach 4.8 and $5.8 \mathrm{~m}^{2} / \mathrm{g}$ for large externally and internally mixed particles, respectively. Even for compact $\mathrm{BC}$ core, the $\delta_{\mathrm{MAC}}$ estimated using the Mie AAE methods can reach approximately $2.8 \mathrm{~m}^{2} / \mathrm{g}$ for large particles. The WDA method does not necessarily improve the estimations. In many cases, the WDA method even provides a worse estimation than the $\mathrm{AAE}=1$ and Mie $\mathrm{AAE}$ methods, and the deviation of $\mathrm{BrC}$ MAC estimated using the WDA method can reach approximately $9 \mathrm{~m}^{2} / \mathrm{g}$ for externally mixed particles. As recent studies have shown that BC commonly exhibits a fluffy structure but not a spherical structure, the estimation of $\mathrm{BrC}$ absorption based on the AAE method should carefully consider the effects of BC morphologies. Our findings can guide the use of different AAE methods.

By comparing the AAE/WDA of spherical BC and detailed $\mathrm{BC}$ morphologically realistic models, we have provided explanations for why the good or bad estimations were caused. The AAE does not deviate significantly from 1 if BC presents a fluffy fractal structure, while it varies considerably with $D_{\mathrm{V}}$ if $\mathrm{BC}$ exhibits a spherical structure, and the $\mathrm{AAE}$ value of spherical $\mathrm{BC}$ can vary from a negative value to approximately 1.4. Our results also show that the WDA of fluffy BC and spherical BC exhibit rather different values. For both externally and internally mixed particles, the WDA does not deviate significantly from 0 if the $\mathrm{BC}$ core presents a fluffy structure, while the WDA of spherical BC can vary considerably with the particle size changing, and this may account for the inaccurate $\mathrm{BrC}$ absorption estimations using the WDA method. Our results can provide useful advice on 

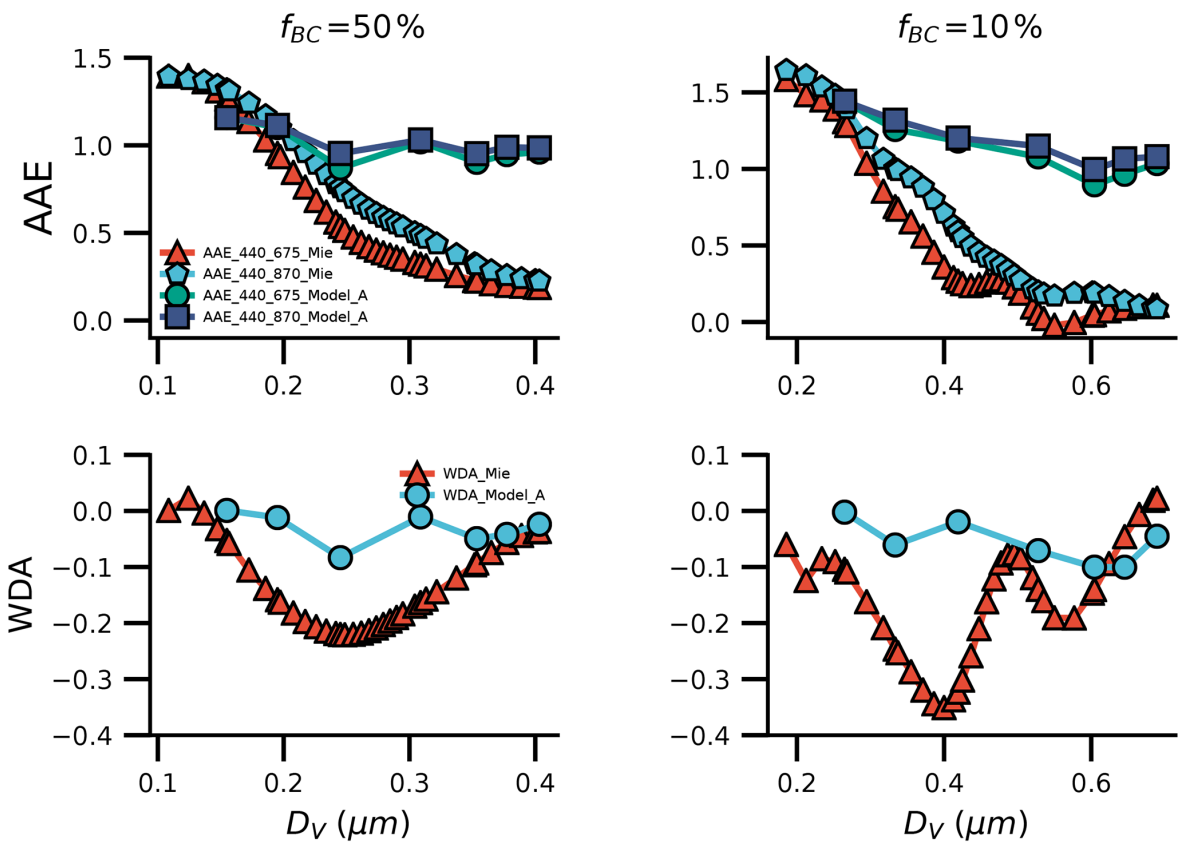

Figure 10. Comparison of AAE and WDA between core-shell sphere model and Model A. Here WDA represents the AAE difference between the $440-675 \mathrm{~nm}$ wavelength pair and the $440-870 \mathrm{~nm}$ wavelength pair.

analyzing why the deviation between the estimated $\mathrm{BrC}$ absorption based on AAE methods and direct measurements is caused.

Data availability. Our calculations were performed using MSTM version 3.0 and DDSCAT 7.3. MSTM version 3.0 can be found online (http://www.eng.auburn.edu/ dmckwski/scatcodes/, Mackowski, 2013), and DDSCAT 7.3 can be obtained from http://ddscat.wikidot.com/ (Draine and Flatau, 2021). Our calculation results can be downloaded from https://doi.org/10.6084/m9.figshare.12839570.v2 (Luo, 2020).

Author contributions. JL and QZ conceived the research idea. JL performed the computations and wrote the paper. $\mathrm{YZ}$ verified the simulation methods and results. QZ reviewed the paper and supervised the findings of this work. All authors discussed the results and contributed to the final paper.

Competing interests. The authors declare that they have no conflict of interest.

Acknowledgements. We particularly thank Daniel W. Mackowski and Michael I. Mishchenko for the MSTM code and thank Bruce Draine and Pjotr Flatau for the DDSCAT software. We also acknowledge the support of the super computing center of the University of Science and Technology of China.
Financial support. This research has been supported by the National Natural Science Foundation of China (grant no. 41675024), the National Natural Science Foundation of China (grant no. U1733126), and the University of Science and Technology of China (grant no. WK2320000052).

Review statement. This paper was edited by Christina McCluskeys and reviewed by two anonymous referees.

\section{References}

Adachi, K., Chung, S. H., Friedrich, H., and Buseck, P. R.: Fractal parameters of individual soot particles determined using electron tomography: Implications for optical properties, J. Geophys. Res.-Atmos., 112, D14202, https://doi.org/10.1029/2006JD008296, 2007.

Arola, A., Schuster, G., Myhre, G., Kazadzis, S., Dey, S., and Tripathi, S. N.: Inferring absorbing organic carbon content from AERONET data, Atmos. Chem. Phys., 11, 215-225, https://doi.org/10.5194/acp-11-215-2011, 2011.

Bahadur, R., Praveen, P. S., Xu, Y., and Ramanathan, V.: Solar absorption by elemental and brown carbon determined from spectral observations, P. Natl. Acad. Sci. USA, 109, 17366-17371, 2012.

Bi, L., Lin, W., Wang, Z., Tang, X., Zhang, X., and Yi, B.: Optical Modeling of Sea Salt Aerosols: The Effects of Nonsphericity and Inhomogeneity, J. Geophys. Res.-Atmos., 123, 543-558, https://doi.org/10.1002/2017JD027869, 2018. 
Bond, T. C. and Bergstrom, R. W.: Light absorption by carbonaceous particles: An investigative review, Aerosol Sci. Tech., 40, 27-67, https://doi.org/10.1080/02786820500421521, 2006.

Chakrabarty, R. K., Moosmuller, H., Garro, M. A., Arnott, W. P., Walker, J., Susott, R. A., Babbitt, R. E., Wold, C. E., Lincoln, E. N., and Hao, W. M.: Emissions from the laboratory combustion of wildland fuels: Particle morphology and size, J. Geophys. Res.-Atmos., 111, D07204 https://doi.org/10.1029/2005JD006659, 2006.

Chakrabarty, R. K., Moosmüller, H., Arnott, W. P., Garro, M. A., Slowik, J. G., Cross, E. S., Han, J.-H., Davidovits, P., Onasch, T. B., and Worsnop, D. R.: Light scattering and absorption by fractal-like carbonaceous chain aggregates: comparison of theories and experiment, Appl. Optics, 46, 6990-7006, https://doi.org/10.1364/AO.46.006990, 2007.

Chakrabarty, R. K., Moosmüller, H., Chen, L.-W. A., Lewis, K., Arnott, W. P., Mazzoleni, C., Dubey, M. K., Wold, C. E., Hao, W. M., and Kreidenweis, S. M.: Brown carbon in tar balls from smoldering biomass combustion, Atmos. Chem. Phys., 10, 63636370, https://doi.org/10.5194/acp-10-6363-2010, 2010.

Chen, Y. and Bond, T. C.: Light absorption by organic carbon from wood combustion, Atmos. Chem. Phys., 10, 1773-1787, https://doi.org/10.5194/acp-10-1773-2010, 2010.

Cheng, Y., He, K.-B., Zheng, M., Duan, F.-K., Du, Z.-Y., Ma, Y.-L., Tan, J.-H., Yang, F.-M., Liu, J.-M., Zhang, X.-L., Weber, R. J., Bergin, M. H., and Russell, A. G.: Mass absorption efficiency of elemental carbon and water-soluble organic carbon in Beijing, China, Atmos. Chem. Phys., 11, 11497-11510, https://doi.org/10.5194/acp-11-11497-2011, 2011.

China, S., Mazzoleni, C., Gorkowski, K., Aiken, A. C., and Dubey, M. K.: Morphology and mixing state of individual freshly emitted wildfire carbonaceous particles, Nat. Commun., 4, 2122 https://doi.org/10.1038/ncomms3122, 2013.

China, S., Salvadori, N., and Mazzoleni, C.: Effect of Traffic and Driving Characteristics on Morphology of Atmospheric Soot Particles at Freeway On-Ramps, Environ. Sci. Technol., 48, 3128-3135, 2014.

China, S., Scarnato, B., Owen, R. C., Zhang, B., Ampadu, M. T., Kumar, S., Dzepina, K., Dziobak, M. P., Fialho, P., Perlinger, J. A., Hueber, J., Helmig, D., Mazzoleni, L. R., and Mazzoleni, C.: Morphology and mixing state of aged soot particles at a remote marine free troposphere site: Implications for optical properties, Geophys. Res. Lett., 42, 1243-1250, https://doi.org/10.1002/2014GL062404, 2015.

Cho, C., Kim, S.-W., Lee, M., Lim, S., Fang, W., Örjan Gustafsson, Andersson, A., Park, R. J., and Sheridan, P. J.: Observation-based estimates of the mass absorption crosssection of black and Brown carbon and their contribution to aerosol light absorption in East Asia, Atmos. Environ., 212, 6574, https://doi.org/10.1016/j.atmosenv.2019.05.024, 2019.

Chung, C. E., Ramanathan, V., and Decremer, D.: Observationally constrained estimates of carbonaceous aerosol radiative forcing, P. Natl. Acad. Sci. USA, 109, 11624-11629, 2012.

Draine, B. T. and Flatau, P. J.: Discrete-Dipole Approximation for Scattering Calculations, J. Opt. Soc. Am., 11, 1491-1499, 1994.

Draine, B. T. and Flatau, P. J.: Discrete-dipole approximation for periodic targets: theory and tests, J. Opt. Soc. Am., 25, 26932703, 2008.
Draine, B. T. and Flatau, P. J.: DDSCAT: light scattering code, available at: http://ddscat.wikidot.com/, last access: 1 April 2021.

Du, Z., He, K., Cheng, Y., Duan, F., Ma, Y., Liu, J., Zhang, X., Zheng, M., and Weber, R.: A yearlong study of water-soluble organic carbon in Beijing II: Light absorption properties, Atmos. Environ., 89, 235-241, https://doi.org/10.1016/j.atmosenv.2014.02.022, 2014.

Feng, Y., Ramanathan, V., and Kotamarthi, V. R.: Brown carbon: a significant atmospheric absorber of solar radiation?, Atmos. Chem. Phys., 13, 8607-8621, https://doi.org/10.5194/acp13-8607-2013, 2013.

He, C., Liou, K.-N., Takano, Y., Zhang, R., Levy Zamora, M., Yang, P., Li, Q., and Leung, L. R.: Variation of the radiative properties during black carbon aging: theoretical and experimental intercomparison, Atmos. Chem. Phys., 15, 11967-11980, https://doi.org/10.5194/acp-15-11967-2015, 2015.

He, C., Takano, Y., Liou, K.-N., Yang, P., Li, Q., and Mackowski, D. W.: Intercomparison of the GOS approach, superposition Tmatrix method, and laboratory measurements for black carbon optical properties during aging, J. Quant. Spectrosc. Ra., 184, 287-296, https://doi.org/10.1016/j.jqsrt.2016.08.004, 2016.

Intergovernmental Panel on Climate Change (IPCC): Climate Change 2013 - The Physical Science Basis: Working Group I Contribution to the Fifth Assessment Report of the Intergovernmental Panel on Climate Change, Cambridge University Press, https://doi.org/10.1017/CBO9781107415324, 2014.

Kahnert, M.: On the Discrepancy between Modeled and Measured Mass Absorption Cross Sections of Light Absorbing Carbon Aerosols, Aerosol Sci. Tech.y, 44, 453-460, 2010.

Kirchstetter, T. W., Novakov, T., and Hobbs, P. V.: Evidence that the spectral dependence of light absorption by aerosols is affected by organic carbon, J. Geophys. Res.-Atmos., 109, D21208, https://doi.org/10.1029/2004JD004999, 2004.

Lack, D. A. and Cappa, C. D.: Impact of brown and clear carbon on light absorption enhancement, single scatter albedo and absorption wavelength dependence of black carbon, Atmos. Chem. Phys., 10, 4207-4220, https://doi.org/10.5194/acp10-4207-2010, 2010.

Lack, D. A., Cappa, C. D., Cross, E. S., Massoli, P., Ahern, A. T., Davidovits, P., and Onasch, T. B.: Absorption Enhancement of Coated Absorbing Aerosols: Validation of the Photo-Acoustic Technique for Measuring the Enhancement, Aerosol Sci. Tech., 43, 1006-1012, 2009.

Lewis, K. A., Arnott, W. P., Moosmüller, H., Chakrabarty, R. K., Carrico, C. M., Kreidenweis, S. M., Day, D. E., Malm, W. C., Laskin, A., Jimenez, J. L., Ulbrich, I. M., Huffman, J. A., Onasch, T. B., Trimborn, A., Liu, L., and Mishchenko, M. I.: Reduction in biomass burning aerosol light absorption upon humidification: roles of inorganically-induced hygroscopicity, particle collapse, and photoacoustic heat and mass transfer, Atmos. Chem. Phys., 9, 8949-8966, https://doi.org/10.5194/acp-9-89492009, 2009.

Li, J., Liu, C., Yin, Y., and Kumar, K. R.: Numerical investigation on the Ångström Exponent of black carbon aerosol, J. Geophys. Res.-Atmos., 121, 3506-3518, 2016.

Li, Z., Zhao, X., Kahn, R., Mishchenko, M., Remer, L., Lee, K.H., Wang, M., Laszlo, I., Nakajima, T., and Maring, H.: Uncertainties in satellite remote sensing of aerosols and impact on monitoring its long-term trend: a review and perspective, 
Ann. Geophys., 27, 2755-2770, https://doi.org/10.5194/angeo27-2755-2009, 2009.

Liu, C., Chung, C. E., Yin, Y., and Schnaiter, M.: The absorption Ångström exponent of black carbon: from numerical aspects, Atmos. Chem. Phys., 18, 6259-6273, https://doi.org/10.5194/acp18-6259-2018, 2018.

Liu, L. and Mishchenko, M.: Scattering and radiative properties of morphologically complex carbonaceous aerosols: a systematic modeling study, Remote Sensing, 10, 1634, https://doi.org/10.3390/rs10101634, 2018.

Liu, L. and Mishchenko, M. I.: Effects of aggregation on scattering and radiative properties of soot aerosols, J. Geophys. Res.Atmos., 110, D11211, https://doi.org/10.1029/2004JD005649, 2005.

Luo, J.: Dataset for the calculations of MSTM and DDSCAT, Figshare, https://doi.org/10.6084/m9.figshare.12839570.v1, 2020.

Luo, J., Zhang, Y., Wang, F., Wang, J., and Zhang, Q.: Applying machine learning to estimate the optical properties of black carbon fractal aggregates, J. Quant. Spectrosc. Ra., 215, 1-8, 2018a.

Luo, J., Zhang, Y., Wang, F., and Zhang, Q.: Effects of brown coatings on the absorption enhancement of black carbon: a numerical investigation, Atmos. Chem. Phys., 18, 16897-16914, https://doi.org/10.5194/acp-18-16897-2018, 2018 b.

Luo, J., Zhang, Y., and Zhang, Q.: A model study of aggregates composed of spherical soot monomers with an acentric carbon shell, J. Quant. Spectrosc. Ra., 205, 184-195, https://doi.org/10.1016/j.jqsrt.2017.10.024, 2018c.

Luo, J., Zhang, Q., Luo, J., Liu, J., Huo, Y., and Zhang, Y.: Optical Modeling of Black Carbon With Different Coating Materials: The Effect of Coating Configurations, J. Geophys. Res.-Atmos., 124, 3230-13253, https://doi.org/10.1029/2019JD031701, 2019.

Luo, J., Zhang, Y., and Zhang, Q.: The Ångström Exponent and Single-Scattering Albedo of Black Carbon: Effects of Different Coating Materials, Atmosphere, 11, 1103, https://doi.org/10.3390/atmos11101103, 2020.

Mackowski, D. W.: MSTM Version 3.0: April 2013, available at: http://www.eng.auburn.edu/ dmckwski/scatcodes/ (last access: 1 April 2021), 2013.

Mackowski, D. W. and Mishchenko, M. I.: Calculation of the T matrix and the scattering matrix for ensembles of spheres, J. Opt. Soc. Am., 13, 2266-2278, 1996.

Mackowski, D. W. and Mishchenko, M. I.: A multiple sphere Tmatrix Fortran code for use on parallel computer clusters, J. Quant. Spectrosc. Ra., 112, 2182-2192, 2011.

Massabò, D., Caponi, L., Bernardoni, V., Bove, M., Brotto, P., Calzolai, G., Cassola, F., Chiari, M., Fedi, M., Fermo, P., et al.: Multi-wavelength optical determination of black and brown carbon in atmospheric aerosols, Atmos. Environ., 108, 1-12, 2015.

Mie, G.: Beiträge zur Optik trüber Medien, speziell kolloidaler Metallösungen, Ann. Phys., 330, 377-445, https://doi.org/10.1002/andp.19083300302, 1908.

Mishchenko, M. I. and Yurkin, M. A.: On the concept of random orientation in far-field electromagnetic scattering by nonspherical particles, Opt. Lett., 42, 494-497, 2017.

Mishchenko, M. I., Travis, L. D., and Lacis, A. A.: Scattering, absorption, and emission of light by small particles, Cambridge university press, 2002.
Nakayama, T., Sato, K., Matsumi, Y., Imamura, T., Yamazaki, A., and Uchiyama, A.: Wavelength and NOx dependent complex refractive index of SOAs generated from the photooxidation of toluene, Atmos. Chem. Phys., 13, 531-545, https://doi.org/10.5194/acp-13-531-2013, 2013.

Russell, P. B., Bergstrom, R. W., Shinozuka, Y., Clarke, A. D., DeCarlo, P. F., Jimenez, J. L., Livingston, J. M., Redemann, J., Dubovik, O., and Strawa, A.: Absorption Angstrom Exponent in AERONET and related data as an indicator of aerosol composition, Atmos. Chem. Phys., 10, 1155-1169, https://doi.org/10.5194/acp-10-1155-2010, 2010.

Saleh, R., Hennigan, C. J., McMeeking, G. R., Chuang, W. K., Robinson, E. S., Coe, H., Donahue, N. M., and Robinson, A. L.: Absorptivity of brown carbon in fresh and photo-chemically aged biomass-burning emissions, Atmos. Chem. Phys., 13, 76837693, https://doi.org/10.5194/acp-13-7683-2013, 2013.

Saleh, R., Marks, M., Heo, J., Adams, P. J., Donahue, N. M., and Robinson, A. L.: Contribution of brown carbon and lensing to the direct radiative effect of carbonaceous aerosols from biomass and biofuel burning emissions, J. Geophys. Res.-Atmos., 120, 10,285-10,296, https://doi.org/10.1002/2015JD023697, 2015.

Schnaiter, M., Horvath, H., Mohler, O., Naumann, K. H., Saathoff, H., and Schock, O. W.: UV-VIS-NIR spectral optical properties of soot and soot-containing aerosols, J. Aerosol Scie., 34, 14211444, 2003.

Sorensen, C. M.: Light Scattering by Fractal Aggregates: A Review, Aerosol Sci. Technol., 35, 648-687, https://doi.org/10.1080/02786820117868, 2001.

Srinivas, B., Rastogi, N., Sarin, M., Singh, A., and Singh, D.: Mass absorption efficiency of light absorbing organic aerosols from source region of paddy-residue burning emissions in the IndoGangetic Plain, Atmos. Environ., 125, 360-370, 2016.

Sumlin, B. J., Heinson, W. R., and Chakrabarty, R. K.: Retrieving the aerosol complex refractive index using PyMieScatt: A Mie computational package with visualization capabilities, J. Quant. Spectrosc. Ra., 205, 127-134, https://doi.org/10.1016/j.jqsrt.2017.10.012, 2018.

Tesche, M., Müller, D., Gross, S., Ansmann, A., Althausen, D., Freudenthaler, V., Weinzierl, B., Veira, A., and Petzold, A.: Optical and microphysical properties of smoke over Cape Verde inferred from multiwavelength lidar measurements, Tellus B, 63, 677-694, https://doi.org/10.1111/j.1600-0889.2011.00549.x, 2011.

Turpin, B. J. and Lim, H.-J.: Species Contributions to $\mathrm{PM}_{2.5}$ Mass Concentrations: Revisiting Common Assumptions for Estimating Organic Mass, Aerosol Sci. Tech., 35, 602-610, https://doi.org/10.1080/02786820119445, 2001.

Wang, J., Nie, W., Cheng, Y., Shen, Y., Chi, X., Wang, J., Huang, X., Xie, Y., Sun, P., Xu, Z., Qi, X., Su, H., and Ding, A.: Light absorption of brown carbon in eastern China based on 3-year multiwavelength aerosol optical property observations and an improved absorption Ångström exponent segregation method, Atmos. Chem. Phys., 18, 9061-9074, https://doi.org/10.5194/acp18-9061-2018, 2018.

Wang, X., Heald, C. L., Sedlacek, A. J., de Sá, S. S., Martin, S. T., Alexander, M. L., Watson, T. B., Aiken, A. C., Springston, S. R., and Artaxo, P.: Deriving brown carbon from multiwavelength absorption measurements: method and application to AERONET 
and Aethalometer observations, Atmos. Chem. Phys., 16, 1273312752, https://doi.org/10.5194/acp-16-12733-2016, 2016.

Wang, Y. Y., Liu, F. S., He, C. L., Bi, L., Cheng, T. H., Wang, Z. L., Zhang, H., Zhang, X. Y., Shi, Z. B., and Li, W. J.: Fractal Dimensions and Mixing Structures of Soot Particles during Atmospheric Processing, Environ. Sci. Tech. Let., 4, 487-493, 2017.

Wentzel, M., Gorzawski, H., Naumann, K.-H., Saathoff, H., and Weinbruch, S.: Transmission electron microscopical and aerosol dynamical characterization of soot aerosols, J. Aerosol Sci., 34, 1347-1370, https://doi.org/10.1016/S0021-8502(03)003604, 2003.

Woźniak, M.: Characterization of nanoparticle aggregates with light scattering techniques, Theses, Aix-Marseille Université, available at: https://tel.archives-ouvertes.fr/tel-00747711 (last access: 1 April 2021), 2012.

Wu, Y., Cheng, T., and Zheng, L.: Light absorption of black carbon aerosols strongly influenced by particle morphology distribution, Environ. Res. Lett., 15, 094051, https://doi.org/10.1088/17489326/aba2ff, 2020.
Yuan, Q., Xu, J., Wang, Y., Zhang, X., Pang, Y., Liu, L., Bi, L., Kang, S., and Li, W.: Mixing state and fractal dimension of soot particles at a remote site in the southeastern Tibetan plateau, Environ. Sci. Technol., 53, 8227-8234, 2019.

Zhang, R. Y., Khalizov, A. F., Pagels, J., Zhang, D., Xue, H. X., and McMurry, P. H.: Variability in morphology, hygroscopicity, and optical properties of soot aerosols during atmospheric processing, P. Natl. Acad. Sci. USA, 105, 10291-10296, 2008.

Zhang, X., Mao, M., Yin, Y., and Tang, S.: The absorption Ångstrom exponent of black carbon with brown coatings: effects of aerosol microphysics and parameterization, Atmos. Chem. Phys., 20, 9701-9711, https://doi.org/10.5194/acp-209701-2020, 2020. 